\author{
AUTHOR(S) GUZIK, JOYCE $A ., X-2$ \\ COX, ARTHUR N., T-6 \\ University of California \\ Los Alamos National Laboratory \\ P. 0. Box 1663 \\ Los Alamos, NM 87544 \\ SUBMITTED TO

\section{IAUI COLLOQUIUM 134 PROCEEDIKGS \\ MITO, JAPAN}

\section{DISC I.AIMER}

This report was prepured as an account of witk sponsored by an agency of the linited States (iovernment. Neither the I/nited Situtes Government nor any hgency thereof. nor any of their employees, makes any warfanly, express of implied, or assumes any legal liability of responsi. bility for the accuracy, completeness, or usefulness of any information, apparatus, proxduct, or proxess disclosed, of represents that its use would mot infringe privalely owned rights. Refer. ence herein to any specific comnercial prod $₫$ ct, proxess, or service by teade name, trademark. munufaclurer, of otherwise dixes not necessurily constitule of imply its endorsement, recom.

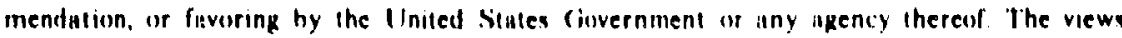
and upinuons of authors expressed herein do llot necessurily state of reflect those uf the United Sitates (iovernment of any ugency therest 


\title{
NONLINEAR RR LYRAE MODELS \\ WITH NEW LIVERMORE OPACITIES
}

\author{
JOYCE A. GUZIK and ARTHUR N. COX \\ Los Alamos National Laboratory
}

\begin{abstract}
A. N. Cox recently showed that a $20 \%$ opacity decrease in the 20,000-50,000 $\mathrm{K}$ region as indicated by the new Livermore OPAL opacities reconciles the discrepancy between pulsation and evolution masses of double-mode RR Lyrae variables. Nonlinear hydrodynamic calculations were performed for RR Lyrae models of mass $0.75 \mathrm{M}_{\odot}, 51 \mathrm{~L}_{\odot}$, and $\mathrm{Z}=0.0001$ (Osterhoff II type) including this opacity decrease. The Stellingwerf periodic relaxation method was used to converge the models to a limit cycle, and the Floquet matrix eigenvalues calculated to search for a a tendency of the fundamental mode to grow from the full-amplitude overtone solution, and the overtone mode to grow from the full-amplitude fundamental solution, thereby predicting double-mode behavior. Models of $\mathrm{T}_{\text {eff }}<7000 \mathrm{~K}$ with the opacity decrease have positive fundamental-mode growth rates in the overtone solution, in contrast to earlier results by Hodson and Cox (1982), and models with $\mathrm{T}_{\text {eff }}>7000$ have positive 1st overtone growth rates in the fundamental-mode solution, but double-mode behaviur was not found.
\end{abstract}

A. N. Cox (1991) recently showed that the $20 \%$ opacity decresse of the new Livermore (1991) opacities compared to the Los Alamos opacities for 'T' $<100,000 \mathrm{~K}$ removes the discrepancy between pulsation and evolution masses of double-mode RR Lyrae variables. This conclusion was verified by Petersen (1992). This paper presents nonlinear calculations for RR Lyrae models of $0.75 \mathrm{M}_{\odot}, 51 \mathrm{~L}_{\odot}$, and $\mathrm{Z}=0.0001$ (Oslerhoff II type) with this opacity decrease to search for a tendency of the fundamental mode to grow from the 
full-amplitude overtone solution, and the overtone mode to grow from the full-amplitude fundamental solution, thereby predicting double-mode behavior.

The 60-zone radiative models have envelope masses 4 to $8 \times 10^{30} \mathrm{~g}$, with wmperature at the base $\sim 600,000 \mathrm{~K}$, and initiai radial velocity amplitudes $20-40 \mathrm{~km} / \mathrm{s}$. The Stellingwerf $(1975 \mathrm{a}, \mathrm{b})$ analytical fit to the CoxTabor (1976) opacity tables is modified by an opacity ramp decreasing from unity to 0.8 between 10,000 and $20,000 \mathrm{~K}$, remaining constant at 0.8 between 20,000 and $30,000 \mathrm{~K}$, and increasing to unity again by $100,000 \mathrm{~K}$.

Comparisons of the Stellingwerf fit to the the OPAL opacities show that the fit is adequate for other temperatures (Iglesias and Rogers, 1991). The nonlinear code described by Ostlie (1990, see also review by Cox and Ostlie, 1992) is used to run several hydrodynamic cycles, to converge to a periodic limit cycle via the Stellingwerf periodic relaxation method, and to check for instability of other modes by analysing the Floquet matrix. The models use artificial viscosity parameters $C_{Q}=4$, and $\alpha=0.02$. The results do not seem to be sensilive to the choice of these parameters, in ccntrast to the findings of Kovacs (1992) and Kovacs and Buchler (1988). Table I summarizes the results for the fundamental and 1 st overtone limit cycles for a grid of models with $\mathrm{T}_{\text {eff }}=6800-7150 \mathrm{~K}$

Table I. Periods, redial velocity amplitudes, and growth rates from Floquet iinatrix for RR Lyrae models.

1st Overtone Solutions

$\begin{array}{lcccc}\mathrm{T}_{\text {eff }}(\mathrm{K}) & \text { Period (d) } & \mathrm{V}_{\min }(\mathrm{km} / \mathrm{s}) & \mathrm{V}_{\max }(\mathrm{km} / \mathrm{s}) & \mathrm{F} \text { in } 1 \mathrm{H} \text { (pe: period) } \\ 6800 & 0.3487 & -21.4 & 20.6 & 0.000955 \\ 6900 & 0.3309 & -20.7 & 20.5 & 0.000687 \\ 7000 & 0.31 \mathrm{c} 3 & -20.9 & 24.1 & -0.000476 \\ 7100 & 0.3019 & -20.5 & 21.6 & -0.000990\end{array}$


Fundamental Mode Solutions

$\begin{array}{lcccc}\mathrm{T}_{\text {eff }}(\mathrm{K}) & \text { Period (d) } & \mathrm{V}_{\min }(\mathrm{km} / \mathrm{s}) & \mathrm{V}_{\max }(\mathrm{km} / \mathrm{s}) & 1 \mathrm{H} \text { in } \mathrm{F} \text { (per period) } \\ 6800 & 0.4721 & -34.1 & 41.4 & -0.060858 \\ 6900 & 0.4487 & -31.3 & 38.0 & -0.035650 \\ 7000 & 0.4273 & -27.8 & 31.8 & -0.015758 \\ 7100 & 0.4063 & -20.2 & 23.2 & 0.004022 \\ 7150 & 0.3963 & -2.9 & 2.8 & 0.015353\end{array}$

In their nonlinear investigation of RR Lyrae models, Hodson and Cox (1982) did not find an effective temperature region with positive fundamental growth rates in the first overtone solution. We find that the $20 \%$ opacity decrease for $\mathrm{T}<100,000 \mathrm{~K}$ indicated by the OPAL opacities causes the fundamental mode growth $\iota$ ates in the first overtone solutions to becomes positive for models with $\mathrm{T}_{\text {eff }}$ less than $7000 \mathrm{~K}$. Still, we ind no overlapping effective temperature region where the overtone mode is predicted to grow from the fundamental mode solution. Opacity adjustments such as widening or deepening the ramp on the Stellingwerf fit do change the growth rates somewhat. For example, widening the temperature range with the full $20 \%$ decrease to between 10,000 and 40,000 , makes the $1 \mathrm{H}$ in $\mathrm{F}$ growth rate/period at $7000 \mathrm{~K}$ slightly less negative ( $\because$ 10037), and the $F$ in $1 \mathrm{H}$ growth rate/period positive (0.0023). Additional studies are in progress.

In this study and in the analysis of Cox (1991), jt appears most promising to search for double-mode RR Lyrae models just redward of fundamental blue odge, at $\mathrm{T}_{\text {eff }}-7000 \mathrm{~K}$, whereas Kovacs and Buchler (1988) and Kovacs (1992) find double-mode behavior for much cooler models ( $\mathrm{T}_{\mathrm{eff}}=$ $6100-6500 \mathrm{~K})$. 


\section{References}

Cox, A. N. 1991, ApJ 381, 171.

Cox, A. N. and Ostlie, D. A. "A Linear and Nonlinear Study of Mira," Nonlinear Phenomena in Stellar Variability, IAU 134, Mito, Japan, Jan. $7-10,1992$.

Iglesias, C. A. and Rogers, F. J. 1991, ApJ 371, L73

Kovacs, G. and Buchler, J. R. 1988, ApJ 324, 1026.

Kovacs, G. "Double-Mode Stellar Pulsation," Nonlinear Phenomena in Stellar Variability, IAU 134, Mito, Japan, Jan. 7-10, 1992.

Ostlie, D. A. 1990, "Time-Dependent Convection in Stellar Pulsation," in proceedings of conference in Les Arcs, France.

Petersen, J. O. 1992, "Kappa-Effect Functions for Period Fatios," preprint.

Steilingwerf, R. F. 1975a, ApJ 195, 441.

Stellingwerf, R. F. 1975b, ApJ 199, 705. 